\title{
RANCANG BANGUN PENGATUR SUHU KANDANG AYAM UNTUK PERTERNAKAN AYAM SKALA KECIL
}

\author{
Nina Lestari ${ }^{1}$, Ketut Abimanyu ${ }^{2}$, Iqra Hadi Setyo ${ }^{2}$, Deden Hadian ${ }^{3}$ \\ Program Studi Teknik Elektro, Universitas Sangga Buana \\ korespondensi : ninalestari28@gmail.com
}

\begin{abstract}
ABSTRAK
Ayam broiler merupakan jenis ayam ternak yang pertumbuhannya dipengaruhi oleh suhu lingkungan, sehingga pengaturan suhu kandang perlu dilakukan untuk menghindari turunnya produktivitas bahkan resiko kematian ayam ternak. Sistem pangatur suhu kandang menggunakan mikrokontroler ATmega 328, sensor suhu LM35, switch kipas / blower dan lampu pijar diatur dengan Relay. Jika suhu yang terukur diatas $29^{\circ} \mathrm{C}$, relay akan diperintahkan oleh mikrokontroler untuk menyalakan atau mematikan kipas/blower dan jika suhu yang terukur dibawah $26^{\circ} \mathrm{C}$, relay akan diperintahkan untuk menyalakan atau mematikan lampu pijar. Berdasarkan hasil penelitian, tingkat kesuksesan alat sistem pengaturan suhu otomatis ini dalam bekerja untuk mengatur suhu kandang ayam secara otomatis adalah sebesar $99.73 \%$ dan error $0.27 \%$.
\end{abstract}

keywords : Ayam, Kipas, Lampu, Suhu

\section{PENDAHULUAN}

Berternak ayam merupakan salah satu kegiatan yang masih banyak dilakukan oleh masyarakat desa ataupun masyarakat umum yang ingin berbisnis di bidang peternakan ayam, khususnya di Indonesia karena rata-rata manusia mengkonsumsi daging ayam hampir setiap hari, sehingga bisnis ini sangat menguntungkan bagi peternaknya. Meskipun kegiatan berternak ini cukup sederhana, banyak orang yang mempermasalahkan tentang bagaimana merawat ayam ternak yang berumur kurang dari satu minggu atau baru menetas dari telurnya, karena suhu tubuhnya belum bisa diatur sendiri.

Oleh karena itu anak ayam tersebut memerlukan kandang yang dapat membuatnya tetap membuatnya tetap dalam keadaan nyaman. Ketika masa brooding, suhu yang diperlukan ayam broiler ialah antara $31^{\circ} \mathrm{C}-33^{\circ} \mathrm{C}$ dan pada masa setelah brooding, suhu yang diperlukan antara $26^{\circ} \mathrm{C}-29^{\circ} \mathrm{C}$. hal tersebut akan membentuk zona nyaman bagi anak ayam, dan dapat pertumbuhan serta perkembangan anak ayam broiler semakin efektif, sehingga hal ini akan mempercepat keuntungan peternaknya Selain itu permasalahan lain yang dialami oleh para peternak ayam yaitu ketika si peternak memiliki lahan peternakan yang jauh dari tempat tinggalnya, sehingga membuat peternak tersebut harus bolak-balik untuk melihat kondisi peternakannya ataupun membuat peternak ayam menyewa banyak karyawan untuk mengurusi peternakannya sehingga akan berdampak pada berkurangnya pendapatan tiap bulannya. Berdasarkan permasalahan tersebut, maka pada perancangan ini akan dibuat suatu alat pada kandang ayam yang bertujuan untuk tetap mengatur kestabilan suhu kandang secara 
otomatis, sehingga situasi kandang masih berada di zona nyaman ayam.

Rancang bangun pengatur suhu otomatis digunakan untuk mengatur pemanas dan pendingin kandang. Dalam perancangan alat, digunakan saklar dan sensor suhu ruang untuk mengatur kestabilan suhu yaitu berupa sensor LM35, karena sensor suhu LM35 memiliki range pengukuran $-55^{\circ} \mathrm{C}$ hingga $+150^{\circ} \mathrm{C}$ dengan akurasi $\pm 0.5^{\circ} \mathrm{C}$ dan bila dibandingkan dengan sensor suhu lainnya (contoh : Termokopel, RTD, Termistor, dll). sensor suhu LM35 mudah ketika perancangan. Memiliki linieritas tinggi dan keluaran impedansi rendah sensor suhu LM35 bisa dikoneksikan dengan rangkaian pengendali khusus dan tidak diperlukan tambahan pengaturan karenak keluarannya berkarakter linier dengan perubahan $10 \mathrm{mV} /{ }^{\circ} \mathrm{C}$.

\section{TINJAUAN PUSTAKA}

\section{Perternakan Ayam Skala Kecil}

Peternakan ayam skala kecil banyak dilakukan oleh banyak pebisnis ternak sampai menjadi peternakan ayam skala besar hal ini dikarenakan tingkat kegagalannya sangat sedikit. Jumlah ayam yang dipelihara pada tiap periodenya adalah 100-500 ekor dan setelah 40 hari dipelihara, ayam sudah harus siap dijual ke pasaran, jika tidak cepat dijual maka akan memperpanjang waktu pemberian pakan. Setelah berumur 40 hari konsumsi pakan sangat tinggi dan menjadi beban bagi peternak kecil maupun besar[1].

Ukuran kandang yang ideal adalah 7 ekor $/ \mathrm{m}^{2}$ dengan peralatan di dalam kandang terdiri dari tempat pakan dan minum bagi anak ayam dan ayam dewasa, listrik serta obat-obatan seperti vaksin dan vitamin. Faktor lain yang perlu diperhatikan adalah suhu kandang yang harus dijaga kestabilannya pada kisaran suhu $27^{\circ} \mathrm{C}$, $29^{\circ} \mathrm{C}$, dan $30^{\circ} \mathrm{C}$ untuk mengoptimalkan tumbuh kembang ayam[2].

\section{Ayam Broiler}

Ayam broiler atau ayam pedaging merupakan jenis ayam yang dapat dengan efisien mengubah pakan menjadi daging serta memiliki kemampuan hidup yang tinggi. Biasanya pada usia 28-45 hari ayam ini sudah siap panen dengan berat badannya berkisar 1,2$2 \mathrm{~kg} / \mathrm{ekor}[3]$.

Ayam broiler sangat dipengaruhi oleh suhu lingkungan dalam pertumbuhannya, pertumbuhan ayam dan penggunaan makanan yang efisien secara maksimum tidak akan tercapai apabila pemeliharaan ayam dilakukan pada suhu lingkungan yang tidak sesuai. Apabila ketidaksesaian suhu lingkungan tersebut terjadi maka akan mengakibatkan pertumbuhan ayam menjadi tidak optimal sehingga menyebabkan kematian. 
ISSN 1979-4835

E-ISSN 2721-2335

\section{Arduino UNO}

Arduino Uno adalah board mikrokontroler berbasis ATMega328. Memiliki 14 pin Input/Output Digital. Untuk mendukung mikrokontroler agar dapat digunakan, cukup dengan menghubungkan board Arduino Uno ke komputer dengan menggunakan kabel USB, power supply atau baterai untuk menjalankannya[4].

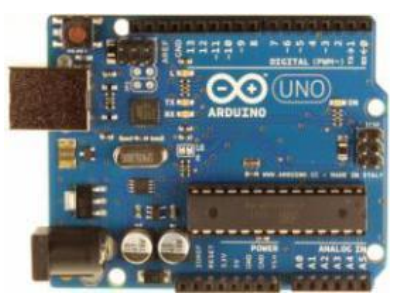

Gambar 1 : Board Arduino Uno

\section{Sensor Suhu LM35}

Merupakan komponen yang dapat mendeteksi perubahan suhu dan mengubahnya menjadi tegangan. Tegangan keluaran yang dihasilkan sebesar $0 \mathrm{mV}$ ketika suhu $0^{\circ} \mathrm{C}$ dan $1000 \mathrm{mV}$ ketika suhu $100^{\circ} \mathrm{C}$. Jadi kenaikan setiap kenaikan suhu $1^{\circ} \mathrm{C}$ akan memberikan kenaikan tegangan $10 \mathrm{mV}$. Pada perancangan kali ini digunakan untuk membaca suhu lingkungan.

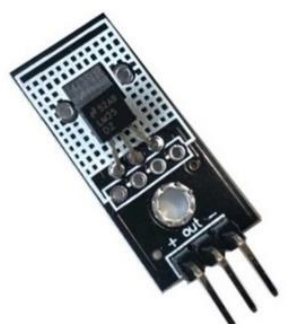

\section{Gambar 2 : Sensor Suhu LM35}

\section{LCD 16x2}

Merupakan modul yang berfungsi untuk menampilkan karakter pada layar yang menggunakan cristal cair. LCD digunakan untuk menampilkan suhu lingkungan yang terbaca.

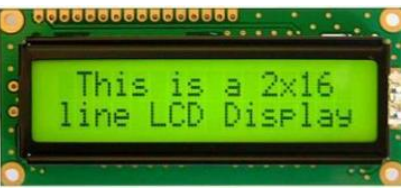

Gambar 3 : LCD 16x2

\section{Relay}


ISSN 1979-4835

E-ISSN 2721-2335

Relay merupakan komponen elektronika yang berfungsi sebagai switch atau saklar yang beroperasi ketika mendapat aliran listrik. Relay 2 channel yang digunakan dalam perancangan kali ini berfungsi untuk menyalakan / mematikan kipas dan lampu secara otomatis sebagai pengatur suhu didalam kandang agar tetap stabil sehingga ayam broiler dapat tumbuh dengan kualitas yang baik[5].

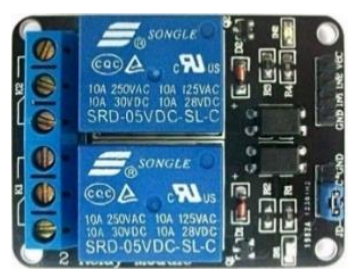

Gambar 4 : Relay 2 Channel

PERANCANGAN SISTEM

Berikut merupakan blok diagram dari sistem yang akan dirancang.

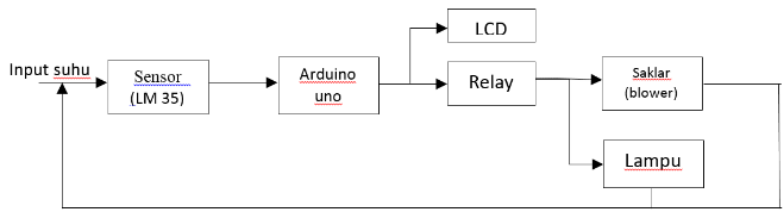

Gambar 6 : Blok Diagram Sistem

Pada rancang bangun pengatur suhu otomatis ATmega328 ini terbagi menjadi dua bagian untuk perternakan ayam sekala kecil dengan menggunakan mikrokontroler berbasis perancangan yakni perancangan perangkat keras dan pembuatan program.

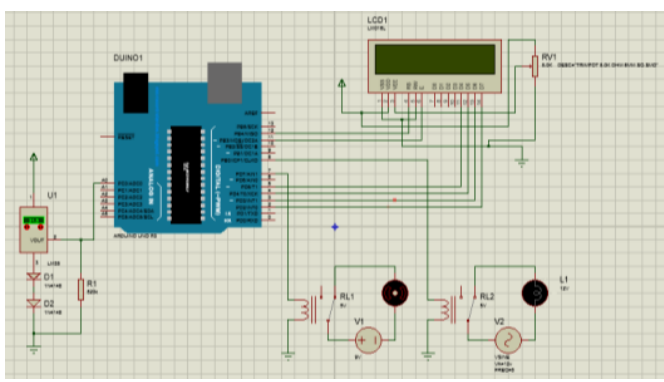

\section{Gambar 7 : Skematik Rangkaian Sistem}

\section{Perancangan Perangkat Keras}

a. Rangkaian Sensor

Rangkaian sensor LM35 berfungsi untuk membaca suhu didalam kandang. Suhu kandang yang terbaca akan dirubah menjadi tegangan dan dijadikan input pada pin A0 mikrokontroler. 


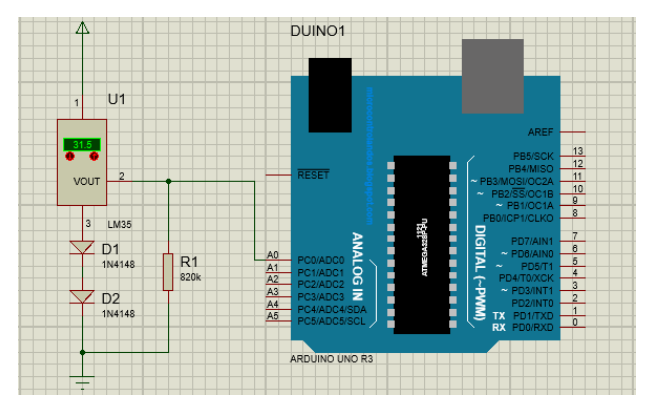

Gambar 8 : Rangkaian Sensor suhu LM35

b. Rangkaian Pengendali

Rangkaian yang digunakan sebagai pengendali adalah mikrokontroler Arduino uno. Rangkaian pengendali ini akan membaca input suhu kandang pada pin A0 dan outputnya untuk menyalakan kipas pada pin 7 dan menyalakan lampu pada pin 8. Sedangkan untuk menampilkan suhu yang terbaca di LCD menggunakan pin 2,3,4,5,11,12.

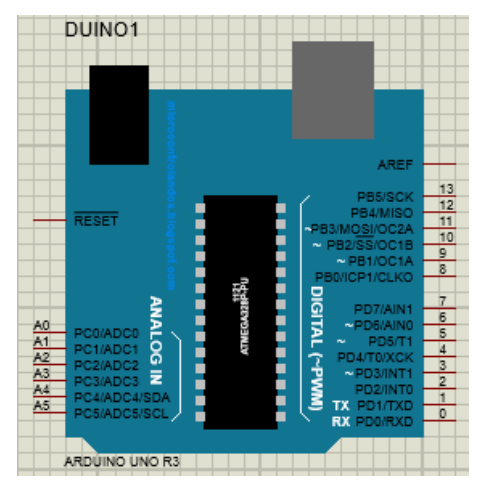

Gambar 9 : Rangkaian sistem minimum mikrokontroler

c. Rangkaian Heater

Rangkaian heater ini menggunakan lampu pijar sebagai indikatornya. Lampu dipasang di titik tertentu supaya pemanasannya merata dan akan menyala ketika suhu kandang kurang dari suhu nyaman untuk ayam yang berfungsi untuk menyesuaikan perubahan suhu agar suhu kandang tetap ideal.

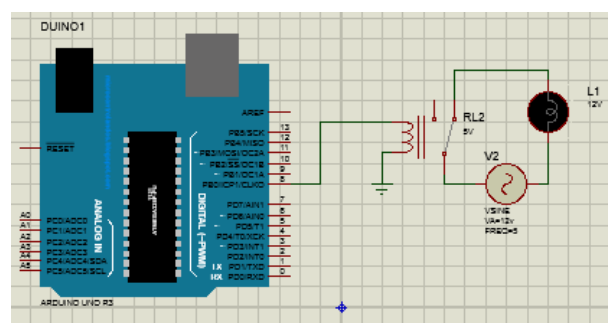

Gambar 10 : Rangkaian Heater

d. Rangkaian Kipas 
ISSN 1979-4835

E-ISSN 2721-2335

Rangkaian Kipas / blower digunakan untuk blower untuk mengeluarkan suhu dalam mendinginkan / menurunkan suhu Jika kandang yang berlebihan[6]. Kipas melebihi batas nyaman suhu kandang untuk ayam ternak, dengan cara mengaktifkan ditempatkan di posisi tertentu agar proses pendinginan dapat merata.

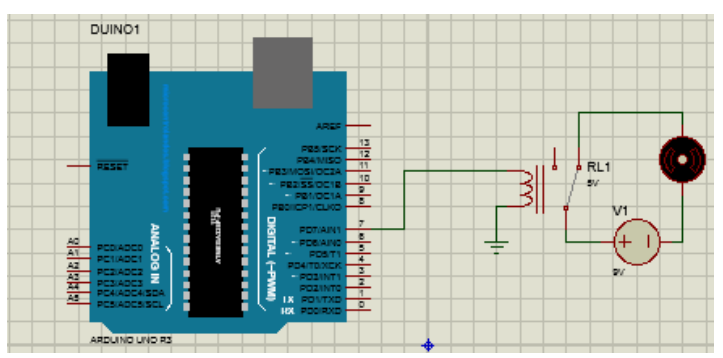

Gambar 11 : Rangkaian Kipas DC

e. Rangkaian LCD

Rangkaian LCD akan menampilkan suhu kandang yang terbaca oleh sensor LM35.
Kecerahan LCD dapat diatur menggunakan potensiometer.

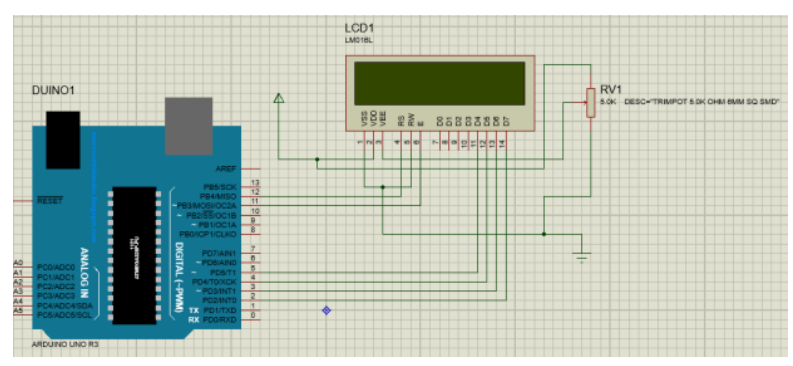

Gambar 12 : Rangkaian LCD

\section{Pembuatan Program}

Program dibuat menggunakan bahasa pemrograman $\mathrm{C}$ untuk memprogram mikrokontroler Arduino uno dalam software IDE Arduino. Pembuatan program harus dilakukan dengan benar agar sistem pengendali ini dapat bekerja dengan baik. Berikut adalah diagram alir tahapan-tahapan dalam pembuatan program. 
ISSN 1979-4835

E-ISSN 2721-2335

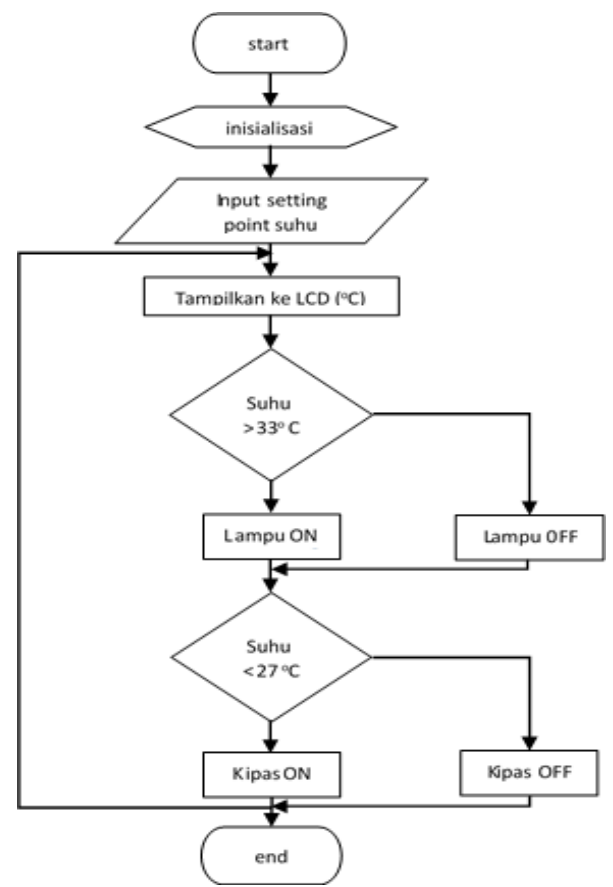

Gambar 13 : Diagram alir pembuatan program Pada Perancangan Sistem

\section{ANALISA DAN PENGUJIAN}

Rangkaian yang dirancang ini akan mendeteksi suhu kandang ayam lalu akan menyalakan atau mematikan kipas atau lampu ketika suhu yang terdeteksi kurang atau melebihi dari suhu nyaman ayam yang ditentukan sebelumnya.

\section{Pengujian Perangkat Keras}

Pengujian dilakukan pada keseluruhan blok diagram yang telah dirancang pada pembahasan sebelumnya

\section{Rangkaian Pengendali Utama}

Pengujian dilakukan dengan cara memeriksa setiap pin yang ada pada mikrokontroler arduino uno apakah berfungsi atau tidak.

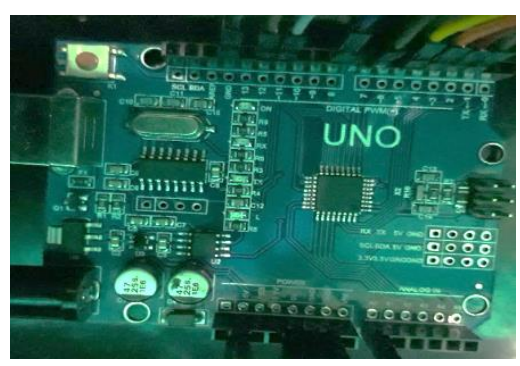

Gambar 14 : Rangkaian sistem minimum mikrokontroler 
Tabel 1 : Hasil pengujian mikrokontroler

\begin{tabular}{|c|c|}
\hline $\begin{array}{c}\text { Mikrokontroler Arduino Uno } \\
\text { (pada Port Digital) }\end{array}$ & $\begin{array}{c}\text { Tegangan } \\
\text { (Volt) }\end{array}$ \\
\hline Logika High & 5 \\
\hline Logika Low & 0 \\
\hline
\end{tabular}

\section{Sensor Suhu LM35}

Pengujian sensor suhu LM35 dilakukan dengan cara membandingkan tingkat akurasi dalam pengukuran suhu antara sensor suhu LM35

dengan termometer digital.

Tabel 2 : Perbandingan nilai suhu terukur

\begin{tabular}{|c|c|}
\hline Sensor LM35 & Termometer Digital \\
\hline $27,93{ }^{\circ} \mathrm{C}$ & $28{ }^{0} \mathrm{C}$ \\
\hline $28,41{ }^{\circ} \mathrm{C}$ & $28,1{ }^{\circ} \mathrm{C}$ \\
\hline $28,20{ }^{\circ} \mathrm{C}$ & $28,8{ }^{\circ} \mathrm{C}$ \\
\hline $28,44{ }^{\circ} \mathrm{C}$ & $28,8{ }^{\circ} \mathrm{C}$ \\
\hline $28,39{ }^{\circ} \mathrm{C}$ & $28,2{ }^{\circ} \mathrm{C}$ \\
\hline
\end{tabular}

\section{LCD}

Pengujian LCD dilakukan dengan cara menghubungkan masing-masing pin pada LCD tersebut ke Pin 2,3,4,5,11,12 mikrokontroler.
Setelah kaki-kaki LCD terhubung, lalu memprogram karakter atau tulisan yang ingin ditampilkan pada LCD melalui sebuah mikrokontroler

[7].

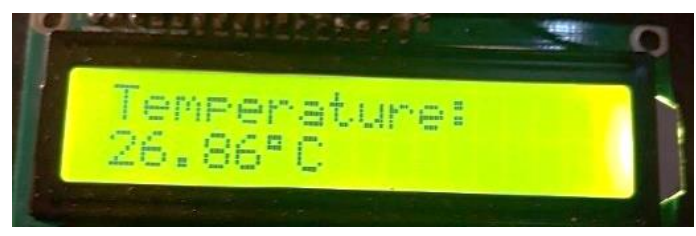

Gambar 15 : Pengujian LCD

\section{Rangkaian Relay}

Pengujian dilakukan dengan memberikan tegangan keluaran dari mikrokontroler sebesar $0 \mathrm{~V}$ maka relay akan berada dalam kondisi off.
Sedangkan ketika tegangan keluaran dari mikrokontroler sebesar $5 \mathrm{~V}$ maka relay akan berada dalam kondisi on. 
ISSN 1979-4835

E-ISSN 2721-2335

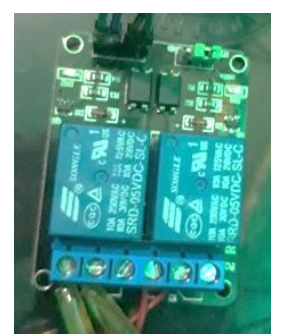

\section{Gambar 16 : Rangkaian Relay 2 channel}

\section{Rangkaian Pemanas (lampu pijar)}

Pengujian dilakukan dengan menurunkan dan menaikan suhu yang dibaca oleh sensor LM35 dari set poin yang ditentukan. Apabila suhu diturunkan dari set poin yang telah ditentukan, maka lampu pijar akan menyala untuk menaikkan suhu kandang dan sebaliknya jika suhu dinaikan, maka lampu pijar akan padam.

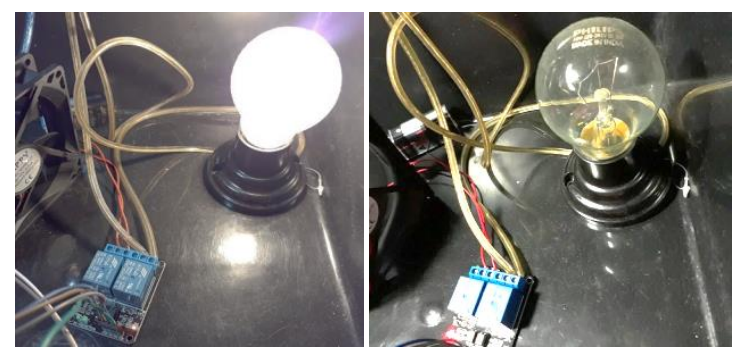

Gambar 17 : Rangkaian lampu pijar

\section{Rangkaian Pendingin (kipas/blower)}

Pengujian kipas ini dilakukan dengan cara menaikkan dan menurunkan suhu yang dibaca sensor LM35 dari set poin yang telah ditentukan. Apabila suhu dinaikkan dari set poin yang telah ditentukan, maka kipas akan menyala untuk menurunkan suhu kandang dan sebaliknya apabila suhu diturunkan dari set poin yang telah ditentukan, kipas akan mati.

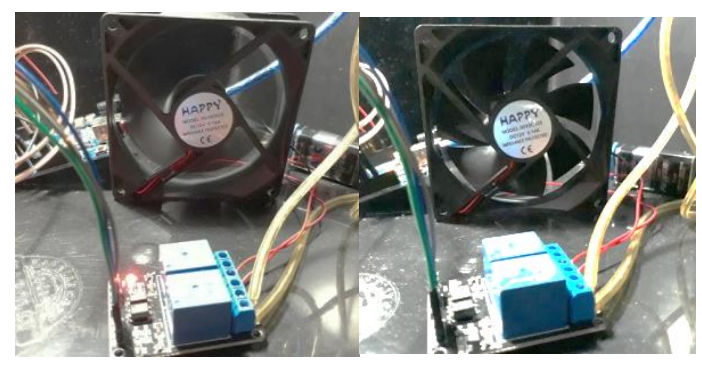

Gambar 18 : Rangkaian Kipas.

\section{Pengujian Alat}


Pada rangkaian ini input A0 (sensor LM35) akan bekerja untuk memberikan masukan high atau low kepada mikrokontroler. Pemograman suhu dilakukan untuk menentukan batasan suhu yang akan digunakan untuk menjaga suhu kandang agar tetap stabil pada batas suhu yang ditentukan. Umur dan kondisi nyaman ayam menjadi dasar penentuan batas suhu.

Tabel 3 : Pengujian sistem dengan batasan suhu $26-29^{\circ} \mathrm{C}$

\begin{tabular}{|c|c|c|c|c|}
\hline Waktu & $\begin{array}{c}\text { Suhu } \\
\text { Ling- } \\
\text { kungan } \\
\left({ }^{\circ} \mathrm{C}\right)\end{array}$ & $\begin{array}{c}\text { Suhu } \\
\text { Kan- } \\
\text { dang } \\
\left({ }^{\circ} \mathrm{C}\right)\end{array}$ & $\begin{array}{c}\text { Suhu } \\
\text { Sensor } \\
\left({ }^{\circ} \mathrm{C}\right)\end{array}$ & Keterangan \\
\hline 00.00 & 20 & 23 & 22,57 & Lampu menyala \\
\hline 04.00 & 17 & 19 & 19,44 & Lampu menyala \\
\hline 08.00 & 22 & 24 & 23,93 & Lampu menyala \\
\hline 12.00 & 31 & 33 & 32,53 & Kipas menyala \\
\hline 16.00 & 27 & 28 & 28,37 & Kondisi Nyaman \\
\hline 20.00 & 21 & 24 & 24,45 & Lampu menyala \\
\hline
\end{tabular}

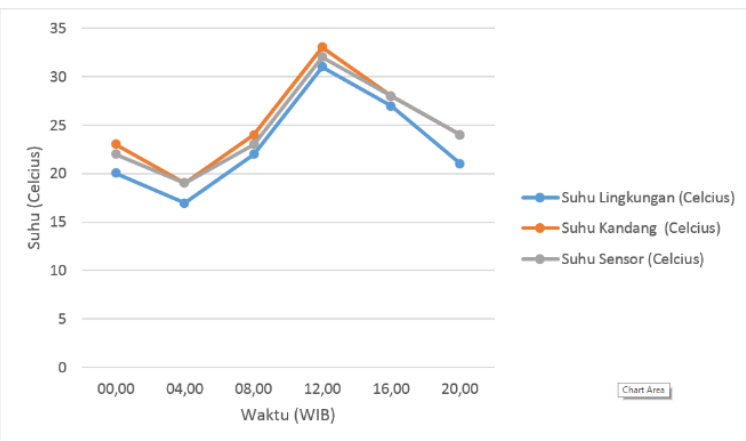

Gambar 19 : Grafik hasil pengukuran suhu dengan batasan suhu $26-29^{\circ} \mathrm{C}$

Dari hasil pengukuran pada tabel 3 dan gambar 19 terlihat bahwa suhu kandang tetap terjaga pada kisaran $26-29^{\circ} \mathrm{C}$ sesuai dengan batas suhu yang ditentukan. Lampu akan otomatis menyala ketika suhu turun dibawah $26^{\circ} \mathrm{C}$ dan akan mati otomatis ketika berada pada suhu $26^{\circ} \mathrm{C}$ keatas. Sedangkan kipas akan menyala otomatis ketika suhu berada diatas $29^{\circ} \mathrm{C}$ dan akan otomatis mati ketika suhu turun dari 29 ${ }^{\mathrm{o}} \mathrm{C}$.

Tabel 4 : Pengujian sistem dengan batasan suhu $29-31^{\circ} \mathrm{C}$ 


\begin{tabular}{|c|c|c|c|c|}
\hline Pukul & $\begin{array}{c}\text { Suhu } \\
\text { Ling- } \\
\text { kungan } \\
\left({ }^{\mathbf{0}} \mathbf{C}\right)\end{array}$ & $\begin{array}{c}\text { Suhu } \\
\text { Kan- } \\
\mathbf{d a n g} \\
\left({ }^{\mathbf{}} \mathbf{C}\right)\end{array}$ & $\begin{array}{c}\text { Suhu } \\
\text { Sensor } \\
\left({ }^{\mathbf{}} \mathbf{C}\right)\end{array}$ & Keterangan \\
\hline 00.00 & 20 & 23 & 23,45 & Lampu menyala \\
\hline 04.00 & 17 & 19 & 19,38 & Lampu menyala \\
\hline 08.00 & 22 & 24 & 24,61 & Lampu menyala \\
\hline 12.00 & 31 & 33 & 33,28 & Kipas menyala \\
\hline 16.00 & 27 & 28 & 27,57 & Lampu menyala \\
\hline 20.00 & 21 & 24 & 24,33 & Lampu menyala \\
\hline
\end{tabular}

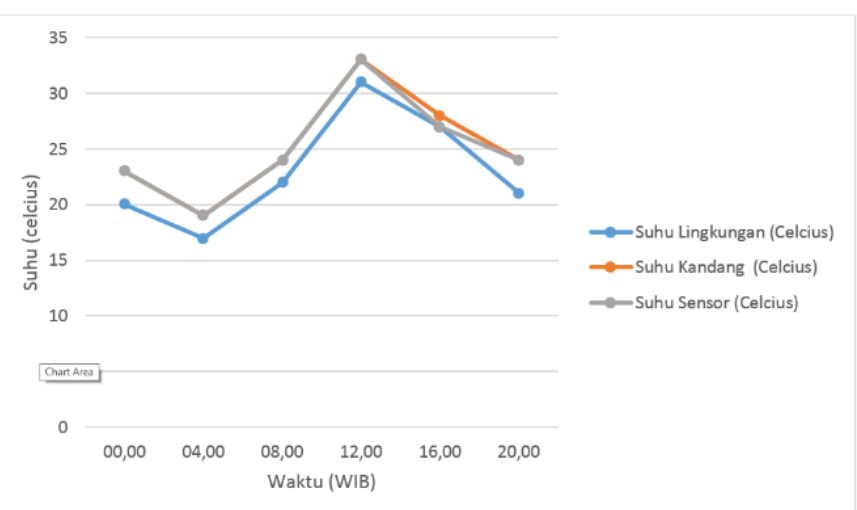

Gambar 20 : Grafik hasil pengukuran suhu dengan batasan suhu $29-31^{\circ} \mathrm{C}$

Dari hasil pengukuran pada tabel 4 dan gambar 20 terlihat bahwa suhu tetap terjaga pada kisaran $29-31{ }^{\circ} \mathrm{C}$ sesuai dengan batas suhu yang ditentukan. Lampu akan otomatis menyala ketika suhu berada dibawah $29^{\circ} \mathrm{C}$ dan akan mati otomatis ketika berada pada suhu $29{ }^{\circ} \mathrm{C}$ keatas. Sedangkan kipas akan menyala otomatis ketika suhu berada diatas $31{ }^{\circ} \mathrm{C}$ dan akan otomatis mati ketika suhuturun dari $31{ }^{\circ} \mathrm{C}$.

Tabel 5 : Pengujian sistem dengan batasan suhu $31-33^{\circ} \mathrm{C}$

\begin{tabular}{|c|c|c|c|c|}
\hline Waktu & $\begin{array}{c}\text { Suhu Lingkungan } \\
(\mathbf{} \mathbf{0})\end{array}$ & $\begin{array}{c}\text { Suhu Kandang } \\
\left({ }^{\mathbf{o}} \mathbf{C}\right)\end{array}$ & $\begin{array}{c}\text { Suhu Sensor } \\
\mathbf{(} \mathbf{C})\end{array}$ & Keterangan \\
\hline 00.00 & 20 & 23 & 23,57 & Lampu menyala \\
\hline 04.00 & 17 & 19 & 18,32 & Lampu menyala \\
\hline 08.00 & 22 & 24 & 23,59 & Lampu menyala \\
\hline 12.00 & 31 & 33 & 32,53 & - \\
\hline 16.00 & 27 & 28 & 28,37 & Lampu menyala \\
\hline 20.00 & 21 & 24 & 23,46 & Lampu menyala \\
\hline
\end{tabular}




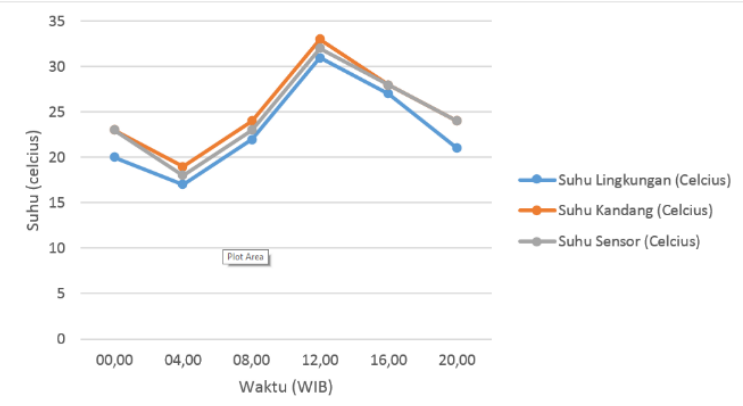

Gambar 21 : Grafik hasil pengukuran suhu dengan batasan suhu $31-33^{\circ} \mathrm{C}$

Dari hasil pengukuran pada tabel 5 dan gambar 21 terlihat bahwa suhu kandang tetap terjaga dengan baik ketika diantara kisaran suhu 31-32 ${ }^{\circ} \mathrm{C}$ sesuai dengan batasan suhu yang telah ditentukan. Lampu akan menyala otomatis ketika suhu berada dibawah $31^{\circ} \mathrm{C}$ dan akan mati otomatis ketika berada pada suhu $31{ }^{\circ} \mathrm{C}$ keatas. Sedangkan kipas akan menyala otomatis ketika suhu berada diatas $33{ }^{\circ} \mathrm{C}$ dan akan mati otomatis ketika berada pada suhu 33 ${ }^{\circ} \mathrm{C}$ kebawah.

Adapun percobaan alat yang dilakukan sebanyak 100x untuk mengukur tingkat keakuratan sensor. Pengukuran suhu dengan batasan suhu $26-29^{\circ} \mathrm{C}$. Apabila suhu $<26^{\circ} \mathrm{C}$, maka lampu pijar akan menyala memanaskan sensor hingga suhu yang dibaca mencapai nilai suhu $26^{\circ} \mathrm{C}$ lalu lampu pijar akan padam, dan apabila suhu $>29^{\circ} \mathrm{C}$, maka kipas akan menyala mendinginkan sensor hingga suhu yang dibaca mencapai nilai $29^{\circ} \mathrm{C}$ lalu kipas akan berhenti. Dengan batasan tersebut maka dilakukan 100x percobaan untuk menguji alat apakah dapat berfungsi semaksimal mungkin, serta menetukan nilai error yang terjadi pada alat.

\section{Tabel 6 : Hasil pengukuran suhu dengan batasan $26-29^{\circ} \mathrm{C}$ sebanyak 100 kali}

\begin{tabular}{|c|c|c|c|c|}
\hline $\begin{array}{c}\text { Tes } \\
\text { Ke- }\end{array}$ & $\begin{array}{c}\text { Tampil } \\
-\mathbf{a n}\left({ }^{\mathbf{0}} \mathbf{C}\right)\end{array}$ & $\begin{array}{c}\text { Pengukur } \\
\text { suhu }\left({ }^{\mathbf{}} \mathbf{C}\right)\end{array}$ & $\begin{array}{c}\text { Kipas / } \\
\text { Lampu }\end{array}$ & $\begin{array}{c}\text { Selisih } \\
\left({ }^{\mathbf{}} \mathbf{C}\right)\end{array}$ \\
\hline 1 & 25.5 & 25.88 & Lampu / ON & 0.38 \\
\hline 2 & 27 & 26.78 & Lampu / OFF & 0.22 \\
\hline 3 & 29.5 & 29.67 & Kipas / ON & 0.17 \\
\hline 4 & 29 & 28.78 & Kipas / OFF & 0.22 \\
\hline 5 & 25 & 25.57 & Lampu / ON & 0.57 \\
\hline 6 & 26.5 & 26.67 & Lampu / OFF & 0.17 \\
\hline 7 & 30 & 29.98 & Kipas / ON & 0.02 \\
\hline 8 & 29 & 28.74 & Kipas / OFF & 0.26 \\
\hline 9 & 26 & 25.78 & Lampu / ON & 0.22 \\
\hline 10 & 26.5 & 26.84 & Lampu / OFF & 0.34 \\
\hline 11 & 29.5 & 30.05 & Kipas / ON & 0.55 \\
\hline 12 & 29 & 28.67 & Kipas / OFF & 0.33 \\
\hline
\end{tabular}

\begin{tabular}{|c|c|c|c|c|}
\hline $\begin{array}{c}\text { Tes } \\
\text { Ke- }\end{array}$ & $\begin{array}{c}\text { Tampil } \\
\text {-an }\left({ }^{\mathbf{}} \mathbf{C}\right)\end{array}$ & $\begin{array}{c}\text { Pengukur } \\
\text { suhu }\left({ }^{\mathbf{}} \mathbf{C}\right)\end{array}$ & $\begin{array}{c}\text { Kipas / } \\
\text { Lampu }\end{array}$ & $\begin{array}{c}\text { Selisih } \\
\left({ }^{\mathbf{} C)}\right.\end{array}$ \\
\hline 13 & 25 & 25.53 & Lampu / ON & 0.53 \\
\hline 14 & 26.5 & 26.84 & Lampu / OFF & 0.34 \\
\hline 15 & 29.5 & 29.98 & Kipas / ON & 0.48 \\
\hline 16 & 28.5 & 28.05 & Kipas / OFF & 0.45 \\
\hline 17 & 25.5 & 25.35 & Lampu / ON & 0.15 \\
\hline 18 & 26 & 26.14 & Lampu / OFF & 0.14 \\
\hline 19 & 29.5 & 29.87 & Kipas / ON & 0.37 \\
\hline 20 & 29 & 28.94 & Kipas / OFF & 0.06 \\
\hline 21 & 25 & 25.19 & Lampu / ON & 0.19 \\
\hline 22 & 26,5 & 26.09 & Lampu / OFF & 0.41 \\
\hline 23 & 29 & 29.4 & Kipas / ON & 0.4 \\
\hline 24 & 28,5 & 28.29 & Kipas / OFF & 0.21 \\
\hline
\end{tabular}


ISSN 1979-4835

E-ISSN 2721-2335

\begin{tabular}{|c|c|c|c|c|}
\hline $\begin{array}{l}\text { Tes } \\
\text { Ke- }\end{array}$ & $\begin{array}{c}\text { Tampil } \\
-\operatorname{an}\left({ }^{\circ} \mathrm{C}\right)\end{array}$ & $\begin{array}{l}\text { Pengukur } \\
\text { suhu }\left({ }^{\circ} \mathrm{C}\right)\end{array}$ & $\begin{array}{l}\text { Kipas / } \\
\text { Lampu }\end{array}$ & $\begin{array}{c}\text { Selisih } \\
\left({ }^{\circ} \mathrm{C}\right)\end{array}$ \\
\hline 25 & 25,5 & 25.29 & Lampu / ON & 0.21 \\
\hline 26 & 27 & 26.5 & Lampu / OFF & 0.5 \\
\hline 27 & 29 & 29.59 & Kipas / ON & 0.59 \\
\hline 28 & 29 & 28.6 & Kipas / OFF & 0.4 \\
\hline 29 & 25 & 25.4 & Lampu / ON & 0.4 \\
\hline 30 & 26.5 & 26.71 & Lampu / OFF & 0.21 \\
\hline 31 & 29.5 & 29.32 & Kipas / ON & 0.18 \\
\hline 32 & 29 & 28.34 & Kipas / OFF & 0.66 \\
\hline 33 & 26 & 25.9 & Lampu / ON & 0.1 \\
\hline 34 & 26.5 & 26.6 & Lampu / OFF & 0.1 \\
\hline 35 & 29.5 & 29.89 & Kipas / ON & 0.39 \\
\hline 36 & 28.5 & 28.58 & Kipas / OFF & 0.08 \\
\hline 37 & 26 & 25.81 & Lampu / ON & 0.19 \\
\hline 38 & 26 & 26.22 & Lampu / OFF & 0.22 \\
\hline 39 & 29 & 29.14 & Kipas / ON & 0.14 \\
\hline 40 & 29 & 28.91 & Kipas / OFF & 0.09 \\
\hline 41 & 25.5 & 25.02 & Lampu / ON & 0.48 \\
\hline 42 & 26 & 26.21 & Lampu / OFF & 0.21 \\
\hline 43 & 29.5 & 29.48 & Kipas / ON & 0.02 \\
\hline 44 & 28 & 27.95 & Kipas / OFF & 0.05 \\
\hline 45 & 26 & 25.77 & Lampu / ON & 0.23 \\
\hline 46 & 26 & 26.12 & Lampu / OFF & 0.12 \\
\hline 47 & 29 & 29.22 & Kipas / ON & 0.22 \\
\hline 48 & 29 & 28.92 & Kipas / OFF & 0.08 \\
\hline 49 & 25.5 & 25.02 & Lampu / ON & 0.48 \\
\hline 50 & 26 & 26.15 & Lampu / OFF & 0.15 \\
\hline 51 & 29.5 & 29.34 & Kipas / ON & 0.16 \\
\hline 52 & 29 & 28.88 & Kipas / OFF & 0.12 \\
\hline 53 & 25 & 25.15 & Lampu / ON & 0.15 \\
\hline 54 & 26.5 & 26.04 & Lampu / OFF & 0.46 \\
\hline 55 & 29.5 & 29.54 & Kipas / ON & 0.04 \\
\hline 56 & 28.5 & 28.84 & Kipas / OFF & 0.34 \\
\hline 57 & 25.5 & 25.44 & Lampu / ON & 0.06 \\
\hline 58 & 27 & 26.57 & Lampu / OFF & 0.43 \\
\hline 59 & 29.5 & 29.74 & Kipas / ON & 0.24 \\
\hline 60 & 29 & 28.22 & Kipas / OFF & 0.78 \\
\hline 61 & 25.5 & 25.64 & Lampu / ON & 0.14 \\
\hline 62 & 26 & 26.43 & Lampu / OFF & 0.43 \\
\hline 63 & 29 & 29.33 & Kipas / ON & 0.33 \\
\hline 64 & 29 & 28.49 & Kipas / OFF & 0.51 \\
\hline
\end{tabular}

\begin{tabular}{|c|c|c|c|c|}
\hline $\begin{array}{l}\text { Tes } \\
\text { Ke- }\end{array}$ & $\begin{array}{l}\text { Tampil } \\
\text {-an }\left({ }^{\circ} \mathbf{C}\right)\end{array}$ & $\begin{array}{l}\text { Pengukur } \\
\text { suhu }\left({ }^{\circ} \mathrm{C}\right)\end{array}$ & $\begin{array}{l}\text { Kipas / } \\
\text { Lampu }\end{array}$ & $\begin{array}{c}\text { Selisih } \\
\left({ }^{\circ} \mathbf{C}\right)\end{array}$ \\
\hline 65 & 25.5 & 25.54 & Lampu / ON & 0.04 \\
\hline 66 & 26 & 26.14 & Lampu / OFF & 0.14 \\
\hline 67 & 29,5 & 29.43 & Kipas / ON & 0.07 \\
\hline 68 & 29 & 28.64 & Kipas / OFF & 0.36 \\
\hline 69 & 26 & 25.95 & Lampu / ON & 0.05 \\
\hline 70 & 26 & 26.05 & Lampu / OFF & 0.05 \\
\hline 71 & 29.5 & 29.16 & Kipas / ON & 0.34 \\
\hline 72 & 29 & 28.96 & Kipas / OFF & 0.04 \\
\hline 73 & 26 & 25.47 & Lampu / ON & 0.53 \\
\hline 74 & 26.5 & 26.07 & Lampu / OFF & 0.43 \\
\hline 75 & 29.5 & 29.78 & Kipas / ON & 0.28 \\
\hline 76 & 28.5 & 28.21 & Kipas / OFF & 0.29 \\
\hline 77 & 26 & 25.57 & Lampu / ON & 0.43 \\
\hline 78 & 26 & 26.18 & Lampu / OFF & 0.18 \\
\hline 79 & 29.5 & 29.67 & Kipas / ON & 0.17 \\
\hline 80 & 28.5 & 28.09 & Kipas / OFF & 0.41 \\
\hline 81 & 25.5 & 25.29 & Lampu / ON & 0.21 \\
\hline 82 & 26 & 26.34 & Lampu / OFF & 0.34 \\
\hline 83 & 29.5 & 29.61 & Kipas / ON & 0.11 \\
\hline 84 & 29 & 28.5 & Kipas / OFF & 0.5 \\
\hline 85 & 26 & 25.88 & Lampu / ON & 0.12 \\
\hline 86 & 26 & 26.32 & Lampu / OFF & 0.32 \\
\hline 87 & 29,5 & 29.71 & Kipas / ON & 0.21 \\
\hline 88 & 29 & 28.02 & Kipas / OFF & 0.98 \\
\hline 89 & 26 & 25.92 & Lampu / ON & 0.08 \\
\hline 90 & 26 & 26.23 & Lampu / OFF & 0.23 \\
\hline 91 & 29.5 & 30.12 & Kipas / ON & 0.62 \\
\hline 92 & 29 & 28.92 & Kipas / OFF & 0.08 \\
\hline 93 & 26 & 25.76 & Lampu / ON & 0.24 \\
\hline 94 & 26 & 26.22 & Lampu / OFF & 0.22 \\
\hline 95 & 29 & 29.5 & Kipas / ON & 0.5 \\
\hline 96 & 28.5 & 28.4 & Kipas / OFF & 0.1 \\
\hline 97 & 26 & 25.51 & Lampu / ON & 0.49 \\
\hline 98 & 26 & 26.09 & Lampu / OFF & 0.09 \\
\hline 99 & 29 & 29.19 & Kipas / ON & 0.19 \\
\hline 100 & 29 & 28.98 & Kipas / OFF & 0.02 \\
\hline \multicolumn{4}{|c|}{ Total } & 27.33 \\
\hline \multicolumn{4}{|c|}{ Nilai error dalam persen $(\%), \sum=$ Total $/ 100$} & $0.27 \%$ \\
\hline \multicolumn{4}{|c|}{$\begin{array}{l}\text { Nilai tingkat akurasi sensor yang di rancang } 100 \% \text { - } \\
\text { Nilai error }\end{array}$} & $\begin{array}{c}99.73 \\
\%\end{array}$ \\
\hline
\end{tabular}


Berdasarkan pengujian yang dilakukan, output pada sensor suhu mempunyai perbedaan. Perbedaan tersebut yakni pada hasil pembacaan sensor suhu LM35 dengan termometer ruangan, namun selisih perbedaannya hanya sedikit. Selain itu, termometer ruangan memerlukan waktu untuk menaikan atau menurunkan suhu saat suhu diturunkan atau dinaikan oleh kipas dan lampu.

\section{KESIMPULAN DAN SARAN}

\section{Kesimpulan}

Diperoleh beberapa kesimpulan, antara lain :

1. Perangkat keras sistem pengatur suhu otomatis kandang ayam dapat berfungsi normal yaitu dapat menjaga kestabilan suhu sesuai dengan batas suhu yang ditentukan.

2. Suhu kandang akan semakin cepat naik ketika suhu lingkungan semakin besar, dan sebaliknya suhu kandang akan semakin lama naik ketika suhu lingkungan semakin kecil.

3. Dari 100 kali percobaan didapatkan nilai tingkat keakuratan sensor sebesar adalah $99.73 \%$ dengan error $0.27 \%$.

\section{Saran}

beberapa saran yang dari hasil pengujian, yaitu:

1. Menambahkan sistem pengukur kelembaban untuk mengetahui kelembaban udara kandang ayam karena pengaruh dari kipas.
2. Menambahkan sistem yang dapat mengirimkan hasil pembacaan suhu berbasis Internet of Things.

3. Membuat sistem pengatur suhu yang dapat berubah sesuai batasan umur ayam.

\section{DAFTAR PUSTAKA}

[1] Kemenristek, "Budidaya Ayam Ras Pedaging," TTG Budid. Peternak., 2000.

[2] Pengantar Peternakan di Daerah tropis, "Pengantar Peternakan di Daerah tropis," in Gajah Mada University Press, Yogyakarta, 2003.

[3] R. K. Sebayang, O. Zebua, and N. Soedjarwanto, "Perancangan Sistem Pengaturan Suhu Kandang Ayam Berbasis Mikrokontroler," JITET J. Inform. Dan Tek. Elektro Terap., 2016.

[4] B. S. Ivany Sarief, Wulandari Pancadasa Merdeka Putri, "Perancangan Dan Realisasi Purwarupa Sistem Monitoring Area Parkir Mobil Dengan Menggunakan Ultrasonik dan Light Dependent Resistor," Infotronik J. Teknol. Inf. dan Elektron., 2018.

[5] S. Hazami, S. Hardienata, and M. I. Suriansyah, "Model Pengatur Suhu Dan Kelembaban Kandang Ayam Broiler Menggunakan Mikrokontroler ATMega328 Dan Sensor DHT11," Univ. Pakuan, 2016.

[6] A. B. Laksono, "Rancang Bangun Sistem Pemberi Pakan Ayam Serta Monitoring Suhu dan Kelembaban Kandang Berbasis Atmega328," $J$. Elektro, 2017, doi: 10.30736/je.v2i2.86.

[7] A. Triyanto and N. Nurwijayanti, "Pengatur Suhu dan Kelembapan Otomatis Pada Budidaya Jamur Tiram Menggunakan Mikrokontroler ATMega16," J. Kaji. Tek. Elektro Univ. Suryadarma Jakarta, 2016. 